\title{
Keratin profiles of normal and malignant oral mucosa using exfoliative cytology
}

\author{
G R Ogden, S McQueen, D M Chisholm, E B Lane
}

\begin{abstract}
Aims-To assess keratin profiles from smears of malignant and contralateral normal oral mucosa as part of the development of a screening procedure for oral cancer based on exfoliative cytology.

Methods-Smears were taken from oral cancers (confirmed by biopsy) and from the contralateral site of 20 patients. Using a panel of antikeratin antibodies, the keratins expressed by these cells were identified using a standard immunocytochemical technique (Vectastain) and assessed on a 3 point scale.

Results-Using $\chi^{2}$ analysis, noticeable differences between the keratin profiles for malignant mucosal smears compared with the contralateral mucosal smears were found. This was particularly evident for the simple epithelial keratins. Conclusion-Individual keratins can be identified in smears from oral cancers. The identification of simple epithelial keratins seem to be the best keratin markers associated with malignancy. Their detection within smears from oral lesions could be valuable in the early diagnosis of oral cancer.
\end{abstract}

(F Clin Pathol 1993;46:352-356)

Worldwide, oral cancer is the 6th most common cancer. ${ }^{1}$ In the United Kingdom about 1900 new cases and 960 deaths occur every year. ${ }^{2}$ Ideally disease prevention is what is required. But there seems little evidence to suggest that exposure to the two factors most frequently associated with oral cancer (alcohol and tobacco) is decreasing. ${ }^{34}$ Even then total reliance on prevention is not possible because all the aetiological factors for oral cancer are not known. ${ }^{56}$

Despite the fact that oral cancer can be cured if treated early enough, ${ }^{7}$ the 5 year survival (about $35 \%)^{8}$ has not really improved with advances in surgery, radiotherapy, and chemotherapy. ${ }^{9}$ The main reason is probably the late presentation of these tumours. ${ }^{1011}$ In turn this may be due to: (i) the asymptomatic nature of the early lesion ${ }^{10}$; (ii) lack of self examination by patients ${ }^{12} 13$; (iii) misdiagnosis by clinician ${ }^{10-12}$; and (iv) the patient's fear. ${ }^{1112}$ These obstacles have to be overcome if the prognosis is to improve.

Recent calls for a screening procedure for oral cancer still rely on subjective assessment by the clinician as to whether the mucosa appears clinically malignant or not. ${ }^{14}{ }^{15}$ Recent advances in the quantitative assessment of oral cytology ${ }^{16-20}$ may offer a suitable technique for such screening, analogous to the screening procedure based on exfoliative cytology for cervical cancer, a disease which may have a similar incidence to oral cancer. ${ }^{14}$ Heavily keratinised oral lesions make it difficult to gain a representative sample of the underlying lesion, but this is offset by their relatively low malignant transformation rateabout $2 \% .{ }^{21}$ Far more worrying are the speckled leucoplakias and erythroplakias which are reported to undergo malignant change more frequently. These lesions are amenable to sampling using exfoliative cytology. Not all general practitioners would biopsy the oral mucosa and they may be more inclined to smear an abnormality of the mucosa. Furthermore, in patients who are under review following treatment of an oral squamous cell carcinoma or in patients who have widespread instability of the oral mucosa, repeat biopsies at every review are not practicable. Such patients would soon fail to attend for review. Exfoliative cytology permits the frequent sampling of such sites with minimal inconvenience to the patient. This forms part of the overall management of our patients treated in Tayside.

As well as assessment of nuclear status, exfoliative cytology samples can be assessed for differentiation status. In epithelial cells differential expression of keratin filament proteins is a well established indicator of differentiation, against which many well characterised antibodies are available. ${ }^{22}{ }^{23}$ Keratins are for the most part conserved during malignant transformation when all other identifying criteria of the cell's origin may have been lost. Because cytokeratin profiles are useful in tumour diagnosis ${ }^{24}$ their identification in oral smears may detect subtle changes in tissues undergoing malignant change.

Keratin expression has been studied in normal oral epithelia, ${ }^{25}$ but keratin antibodies had not previously been applied to smears from oral cancers. Knowledge of the normal keratin profile determined the range of keratins studied.

\section{Methods}

Paired smears were taken from biopsy confirmed oral cancers and from the contralateral mucosal site of 20 patients, using a Cytobrush (MedScand, Colgate Medical Ltd,

Scotland

Accepted for publication 7 October 1992 
Table 1 Range of keratin monoclonal antibodies used for immunoperoxidase staining

\begin{tabular}{|c|c|c|c|c|}
\hline Name & Dilution & Reactivity & Reference & Source \\
\hline $\begin{array}{l}\text { LP34 } \\
\text { AE8 } \\
\text { LH1 } \\
\text { LP2K } \\
\text { CAM5·2 } \\
\text { LE41 } \\
\text { LE61 }\end{array}$ & $\begin{array}{l}1 \text { in } 10 \\
1 \text { in } 50 \\
\text { Undiluted } \\
1 \text { in } 5 \\
\text { Undiluted } \\
\text { Undiluted } \\
\text { Undiluted }\end{array}$ & $\begin{array}{l}5,6,18 \\
13 \\
10 \\
19 \\
7,8 \\
8 \\
18\end{array}$ & 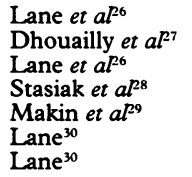 & $\begin{array}{l}\text { EBL } \\
\text { ICN } \\
\text { IL } \\
\text { EBL } \\
\text { ICRF } \\
\text { EBL } \\
\text { EBL }\end{array}$ \\
\hline
\end{tabular}

ICN, High Wycombe, Bucks

ICRF, South Mimms, Herts

Dr I Leigh, Dept of Experimental Dermatology, The Royal

London Hospital

England), and fixed using a commercially available spray fixative containing isopropyl alcohol and polyethylene glycol (Vale Smear Fix, Vale Laboratories, England). Smears were then stored at $-70^{\circ} \mathrm{C}$ until required.

Table 1 shows the range of monoclonal antibodies used to identify the cytokeratin profile (together with dilutions, and source). Goat serum was used as the negative control. Four "wells" were created on each plain glass slide with the aid of a wax pen (PAP pen, Agar Scientific Ltd., England) thus allowing up to four antibodies to be used on each smear.

A standard protocol was followed using avidin biotin visualisation ${ }^{31}$ (Vectastain, Vector Labs., Peterborough, England). Briefly the smears were thawed, fixed in acetone

Table 2 Keratin profiles for each patient for smears from normal $(N)$ and malignant (Les) oral mucosa, together with differentiation status

\begin{tabular}{|c|c|c|c|c|c|c|c|c|}
\hline $\begin{array}{l}\text { Case } \\
\text { number }\end{array}$ & Site & $\begin{array}{l}\text { Differe } \\
\text { status }\end{array}$ & $\begin{array}{l}\text { iation } \\
\qquad A E 8\end{array}$ & $L P 34$ & $L P 2 K$ & $L H 1$ & $C A M 5 \cdot 2$ & $\begin{array}{l}\text { LE41 + } \\
\text { LE61 }\end{array}$ \\
\hline \multirow[t]{2}{*}{1} & LesBM & W & 1 & 2 & 1 & - & 0 & 0 \\
\hline & NBM & & 2 & 2 & 2 & 0 & 0 & 0 \\
\hline \multirow[t]{2}{*}{2} & LesPal & $P$ & 0 & 2 & $\overrightarrow{1}$ & - & 1 & 0 \\
\hline & $\mathrm{NPal}$ & & - & - & - & - & 0 & 0 \\
\hline \multirow[t]{2}{*}{3} & LesPal & W & 0 & 1 & 1 & 0 & 0 & 0 \\
\hline & $\mathrm{NPal}$ & & 1 & 1 & 0 & 0 & - & - \\
\hline \multirow[t]{2}{*}{4} & LesPal & W & 1 & 2 & 1 & 0 & - & - \\
\hline & NPal & & 1 & 1 & 0 & 0 & 0 & 0 \\
\hline \multirow[t]{2}{*}{5} & LesBM & $\mathbf{M}$ & 1 & 2 & 1 & - & 2 & 2 \\
\hline & NBM & & 2 & 2 & 0 & - & 1 & 1 \\
\hline \multirow[t]{2}{*}{6} & LesVT & W & 2 & 2 & 2 & 1 & 1 & 1 \\
\hline & NVT & & 2 & 2 & 2 & 0 & 0 & 0 \\
\hline \multirow[t]{2}{*}{7} & LesBM & W & 0 & 1 & 2 & 2 & 2 & 2 \\
\hline & NBM & & 2 & 2 & 0 & 0 & 0 & 0 \\
\hline \multirow[t]{2}{*}{8} & LesFOM & W & 0 & - & - & 0 & 1 & 1 \\
\hline & NFOM & & 1 & 1 & - & - & - & 0 \\
\hline \multirow[t]{2}{*}{9} & LesFOM & $\mathbf{P}$ & - & 2 & - & 0 & 1 & 1 \\
\hline & NBM & & 2 & 2 & - & 0 & 0 & - \\
\hline \multirow[t]{2}{*}{10} & LesPal & W & 2 & 2 & 2 & 0 & 0 & 0 \\
\hline & NPal & & 1 & 2 & 0 & 0 & 0 & 0 \\
\hline \multirow[t]{2}{*}{11} & LesAlv & W & 0 & $=$ & 1 & 0 & 0 & 1 \\
\hline & NAlv & & 1 & 2 & - & 2 & - & - \\
\hline \multirow[t]{2}{*}{12} & LesVT & W & 1 & 2 & 1 & 0 & 1 & 1 \\
\hline & NVT & & 2 & 2 & 0 & 0 & 0 & 0 \\
\hline \multirow[t]{2}{*}{13} & LesVT & W & 1 & $\overrightarrow{1}$ & 0 & 1 & 0 & 1 \\
\hline & NVT & & 2 & 2 & 0 & 1 & 0 & 0 \\
\hline \multirow[t]{2}{*}{14} & LesPal & W & 1 & 1 & 1 & 1 & 0 & 0 \\
\hline & NPal & & 0 & 2 & 0 & 0 & 0 & 0 \\
\hline \multirow[t]{2}{*}{15} & LesFOM & M & 1 & 2 & 1 & 1 & 0 & 1 \\
\hline & NFOM & & 2 & 2 & 0 & 0 & 0 & 0 \\
\hline \multirow[t]{2}{*}{16} & LesFOM & W & 1 & 0 & 0 & 0 & 0 & 0 \\
\hline & NFOM & & - & 2 & 0 & 0 & 0 & 0 \\
\hline \multirow[t]{2}{*}{17} & LesVT & w & 2 & 2 & 1 & 0 & 1 & 2 \\
\hline & NVT & & 2 & 2 & 1 & 0 & 0 & 0 \\
\hline \multirow[t]{2}{*}{18} & LesBM & $\mathbf{M}$ & 2 & 2 & 2 & 0 & - & 0 \\
\hline & NBM & & 0 & 1 & 0 & 0 & 0 & 0 \\
\hline \multirow[t]{2}{*}{19} & LesVT & W & 1 & 2 & 2 & - & 2 & 2 \\
\hline & NVT & & 2 & 2 & 2 & - & 0 & 0 \\
\hline \multirow[t]{2}{*}{20} & LesFOM & W & 0 & 2 & 1 & 0 & 1 & 0 \\
\hline & NFOM & & 1 & 1 & 0 & 0 & 0 & 0 \\
\hline
\end{tabular}

Key: Site: $\mathrm{BM}=$ Buccal mucosa; $\mathrm{Pal}=$ Palate; $\mathrm{VT}=$ Ventral tongue; FOM = Floor of mouth; Alv = Alveolus. Differentiation status of tumours: $W=$ well differentiated; $M=$ moderately differentiated; $P=$ poorly differentiated. Keratin expression: $0=$ absent, $1=$ few cells positive; $2=$ many cells positive.
(100\%) for 5 minutes, then air dried at room temperature. After incubation with the antibodies shown the peroxidase label distribution was visualised using diaminobenzidine tetrahydrochloride (DAB) substrate. The smears were then lightly counterstained with Mayer's haematoxylin, dehydrated, and mounted in DPX.

The presence of a particular keratin was then assessed according to the number of brown ("positive") cells present, on a 3 point scale: $0=$ no cells positive; $1=$ few cells positive among many negative cells; $2=$ many positive cells. All smears were graded by one author (GRO). Intraobserver error was randomly checked to assess reproducibility. The entire "well" exposed to a particular antikeratin antibody was scanned for the presence of positively stained cells.

The criteria used for selection of patients reported in this study were that: all should have had histological evidence of carcinoma, smears had been taken from tumour and contralateral sites; and that cytokeratin profiles were available. From our cohort of patients, sequentially the first 20 satisfying these criteria were admitted to the series. By chance this resulted in roughly equal numbers from four different sites in the mouth, including the rare site of the soft palate.

\section{Results}

The results for expression of a particular keratin in both the lesional smear (les) and the contralateral normal mucosal smear (N) are given in table 2 and include results for LP34, which acted as the positive control. The results for smears from these two sites in each patient were compared using $\chi^{2}$ analysis. A significant difference between normal and malignant mucosal smears was found for keratin $8 / 18(\mathrm{p}<0.01)$, keratin $19(\mathrm{p}<0.01)$, and keratin $13(\mathrm{p}<0.05)$. For keratin $8 / 18$, the scores for CAM5.2 and LE41/LE61 were averaged for statistical comparison of normal and lesional smears. Although 20 patients were assessed, cells were not always present within the "well" dedicated to that particular antikeratin antibody. Variations in cell density between individual "wells" in one smear and between cases were apparent. When there were insufficient cells to grade the smear no grade was given.

Figure 1 illustrates positive staining with LP34 of both normal cells (centre) and malignant cells (lower right), in a smear (graded 2) taken from a carcinoma of buccal mucosa.

Figure 2 shows positive staining with CAM5.2 together with larger negatively stained cells in a smear (graded 1) taken from a carcinoma of hard palate.

\section{Discussion}

This preliminary report establishes that different keratins can be identified in smears taken from biopsy confirmed oral cancers and that the consequent profile seen is different from that observed in the smears from clini- 


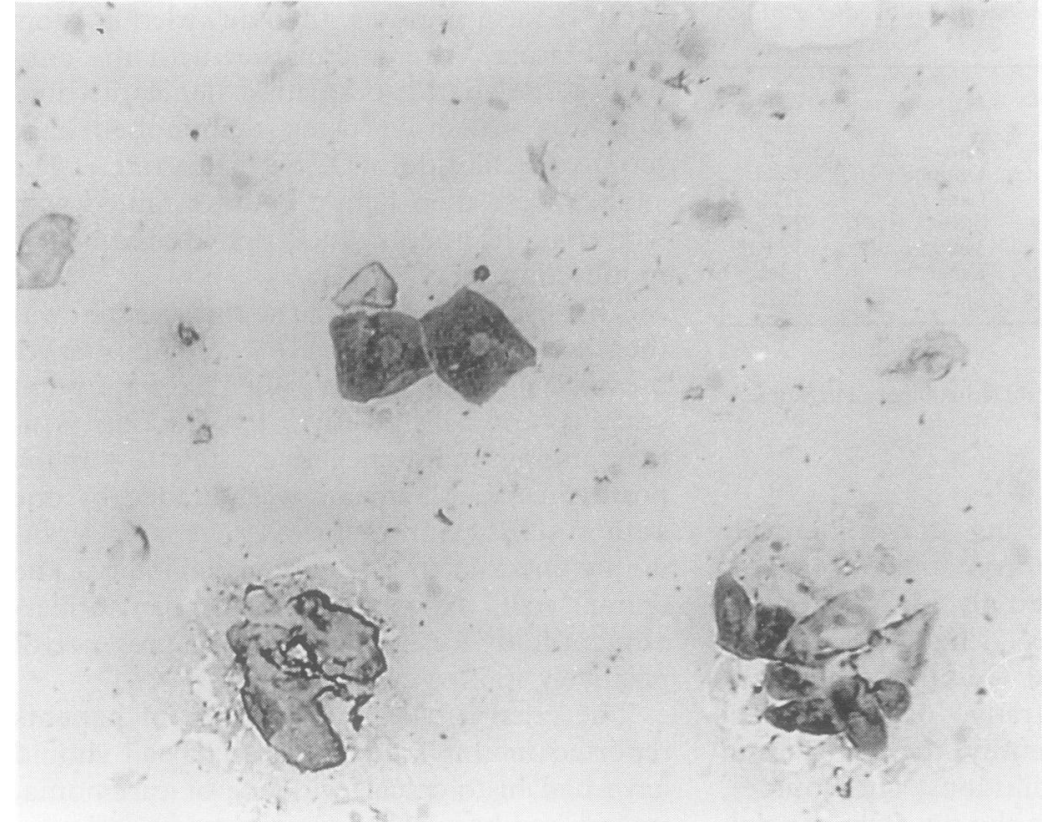

Figure 1 Smear from carcinoma of the buccal mucosa stained with the panepithelial marker LP34.

cally normal oral mucosa.

Although it is recommended that for the identification of a particular keratin more than one antibody recognising that keratin should be used, ${ }^{24}$ there is clearly a limit to the number of smears that can be taken and thus the number of antibodies that can be used. This preliminary study with antibodies to K8, $\mathrm{K} 18, \mathrm{~K} 19, \mathrm{~K} 10, \mathrm{~K} 13$ (plus some mixed ones) was undertaken to evaluate which of the major keratins were likely to yield useful information in a smear assay. These results suggest that the number of antibodies used could be reduced, by concentrating on those identifying the simple epithelial keratins, CAM 5.2, and LP2K proving the stronger antibodies.

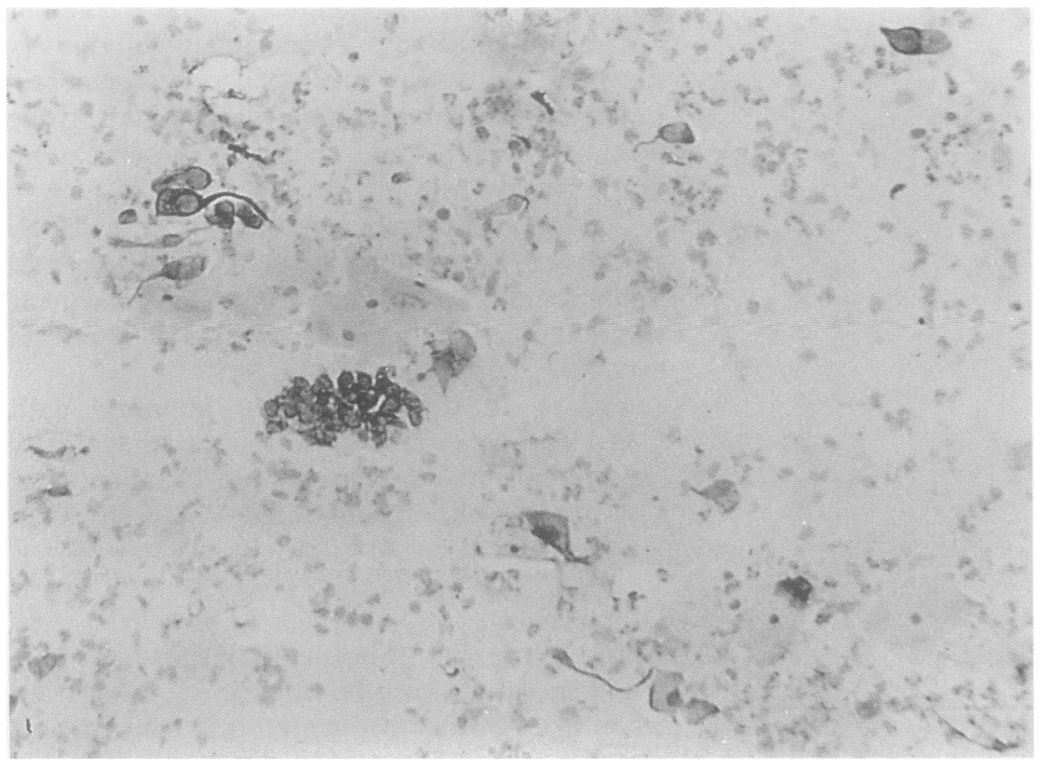

Figure 2 Smear taken from carcinoma of the hard palate with malignant cells stained positively with $C A M 5 \cdot 2$.
Plain glass slides were used at first, with "wells" created by the use of a wax pen. These wells also had the added advantage of limiting the amount of reagent used, and thus the expense of the procedure. However, positive steps had to be taken to avoid bias caused by uneven cell spreading across the slide because the antibodies always followed the same order; those near the boundary of the slide (the marker for keratin 10, LH1) were more likely not to contain sufficient cells on which to grade the expression of that particular keratin. Sampling errors will prejudice the results and possibly limit the value of exfoliative cytology but must be accepted within the limits of the technique. Empty wells occurred in 29 of 240 wells and were excluded from statistical analysis. We have now modified this to use 4-well slides (Hendley Essex), instead of plain slides. Thus the sample instrument makes contact with all four sites that will subsequently receive an antikeratin antibody, which greatly increases the likelihood of cells being present. These smears were taken with the Cytobrush which we have found superior to the traditional wooden spatula. ${ }^{32}$ Another factor to consider with regard to cell yield is that of site. In our experience the hard palate is the site most frequently associated with a poor cell harvest. ${ }^{32}$

The keratins showing the most significant difference between smears from normal and malignant mucosa were the simple keratins 8 , 18 , and 19. This is perhaps not too surprising, given that for normal oral mucosa the other keratins assessed (keratins 10 and 13) are expressed throughout the suprabasal region of keratinsed (K10) and non-keratinised (K13) regions in the oral cavity. ${ }^{25} 33$

In tissue biopsy specimens it has been claimed that well differentiated oral carcinomas express variable mixtures of keratins 10 and $13 .{ }^{34}$ However, as both $\mathrm{K} 10$ and $\mathrm{K} 13$ may be expressed in normal and malignant tissue, this makes them unsuitable as definitive markers of malignancy, particularly as most oral cancers are well differentiated..$^{35}$

Simple keratins (K8 and K18) are not normally expressed in oral mucosa and keratin 19 is limited to the basal cells. ${ }^{25}{ }^{33}$ It has been suggested that suprabasal expression of keratin 19 is associated with malignancy, ${ }^{36}$ and that keratins 8 and 18 do not seem to be found in association with benign mucosal disorders ${ }^{33} 37$ but are associated with many oral cancers. ${ }^{38}$ These simple keratins have also been identified in premalignant lesions. ${ }^{39}$ Thus their identification within a smear of a clinically suspicious lesion would warrant consideration of a biopsy to exclude malignancy.

Because the initial changes which give rise to a clinically visible lesion are thought to occur within the epithelium, ${ }^{40}$ the sampling of individual cells might offer a better chance of detecting malignant change, particularly as over $90 \%$ of all cancers in the oral cavity are squamous cell carcinomas. Oral exfoliative cytology received a great deal of attention in the 1960 s, eventually falling from favour 
due largely to the subjective nature of its interpretation. ${ }^{41}$ There were also difficulties in obtaining a representative sample from hyperkeratotic lesions. However, their rate of malignant transformation is much less than that of speckled leucoplakia and erythroplakia which are amenable to sampling using exfoliative cytology. There is no doubt that histological assessment remains the accepted method of diagnosis. Although the diagnosis of frank oral carcinoma is relatively clear cut, the same is not necessarily true of epithelial dysplasia. ${ }^{4243}$ Hence the development of a reliable test for use in the detection and follow up of malignant lesions, which is pain free, simple, and reproducible, remains the prime objective.

We have previously shown that the use of exfoliative cytology can detect malignant change, ${ }^{1718}$ based on the assessment of nuclear and cytoplasmic areas of Papanicolaou stained cells and DNA profiles of Feulgen stained smears taken from the lesion and compared with those taken from the contralateral normal mucosa. However, continued refinements are required to improve the technique. Ideally, the identification of a marker present in malignant cells but not in normal cells is required.

This preliminary report suggests that further studies on keratin expression in oral exfoliative cytology for the diagnosis of oral cancer should concentrate on keratins 8,18 , and 19 , given their association with malignant disease reported here and in published findings. 22333436384445 The identification of a keratin marker that is lost during malignant transformation-for example, keratin $13^{46}$-is less satisfactory because such keratins can be found in normal mucosa adjacent to the sampled lesion. Such cells might "contaminate" the smear, particularly if the lesion under investigation is small.

The identification of cytokeratin expression in oral exfoliative cytology is encouraging, particularly when such expression seems to be quite robust. ${ }^{47}$ Further studies are currently underway to evaluate these preliminary results and to address the slight variations in the normal group seen in table 2. However, their combination with quantitative cytomorphological assessment ${ }^{17}$ may well contribute towards the development of a screening programme to detect oral cancers at an early stage.

This study was supported in part by the Cunningham Trust and the Medical Research Council. We acknowledge the helpful advice of Dr D Hopwood, Dr J G Cowpe and Dr M W ful advice of Dr D Hopwood, Dr J G Cowpe and Dr M W
Green. We also thank Mrs E Mitchell for typing the manuscript.

1 Boyle P, Macfarlane GJ, Maisonneuve P, Zheng T, Scully C, Tedesco B. Epidemiology of mouth cancer in 1989: a review. F Roy Soc Med 1990;83:724-30.

2 Johnson N. Oral cancer. Cancer Research Campaign Factsheet 14. London: CRC, 1990.

3 Goddard E. Drinking and attitudes to licensing in Scotland. London: HMSO, 1986.

4 Goddard E, Ikin C. Smoking among secondary school children in 1986. London: HMSO, 1987

5 Macfarlane GJ, Boyle P, Scully C. Rising mortality from cancer of the tongue in young Scottish males. Lancet 1987;ii:912.

6 Sankaranarayanan R, Mohideen N, Nair MK,
Padmanabhan TK. Etiology of oral cancer in patients < 30 years of age. Br f Cancer 1989;59:439-40.

7 Stell PM, Wood GD, Scott MH. Early oral cancer: treatment by biopsy excision. $B r \mathcal{F}$ Oral Surg 1982;20:234-6.

8 Johnson N. Orofacial neoplasms: global epidemiology, risk factors and recommendations for research. Final Report of Working Group 2 of The Commission on Oral Health Research and Epidemiology of the Féderation Dentaire Internationale. London: 1990.

9 Stell PM, McCormick MS. Cancer of the head and neck: are we doing any better? Lancet 1985 ;ii:1127.

10 Cooke BED, Tapper-Jones L. Recognition of oral cancer, causes of delay. Br Dent $\mathcal{F}$ 1977;142:96-8.

11 Guggenheimer J, Verbin RS, Johnson JT, Horkowitz CA Myers EN. Factors delaying the diagnosis of oral and Myers EN. Factors delaying the diagnosis of ora
oropharyngeal carcinomas. Cancer 1989;64:932-5.

12 Scully C, Malamos D, Levers BGH, Porter SR, Prime SS Sources and patterns of referrals of oral cancer: role of general practitioners. $\mathrm{Br}$ Med F 1986;293:599-601.

13 Ogden GR, Cowpe JG, Chisholm DM. Cost of oral screening. Lancet 1991;337:920-1.

14 Nally FF. Oral cancer. Br Dent $\mathcal{f} 1988 ; 165: 240$

15 Feaver GP. Screening for oral cancer. Br Med $\mathcal{f} 1989$; 298:603.

16 Cowpe JG, Longmore RB, Green MW. Quantitative exfoliative cytology of normal oral squames: An age, site and sex related survey. $\mathcal{F} R$ Soc Med 1985;78:995-1004.

17 Cowpe JG, Longmore RB, Green MW. Quantitative exfoliative cytology of abnormal oral mucosal smears. $f R$ Soc Med 1988;81:509-13.

18 Ogden GR, Cowpe JG. Quantitative cytophotometric analysis as an aid to the detection of recurrent oral cancer. Br F Oral Maxillofac Surg 1989;27:224-8.

19 Ogden GR, Cowpe JG, Green MW. Effect of radiotherapy on oral mucosa assessed by quantitative exfoliative cytology. F Clin Pathol 1989;42:940-3.

20 Ogden GR, Cowpe JG, Green MW. Detection of field change in oral cancer using oral exfoliative cytology. Cancer 1991;68:1611-5.

21 Hogewind WF, van-der-Kwast WA, van-der-Waal I. Oral leukoplakia, with emphasis on malignant transformation. A follow-up study of 46 patients. $f$ Craniomaxillofac Surg 1989;17:128-33.

22 Cooper D, Schermer A, Sun T-T. Classification of human epithelia and their neoplasms using monoclonal antiepithelia and their neoplasms using monoclonal antibodies to keratins: strategies, app
tions. Lab Invest 1985;52:243-56.

23 Ogden GR, Nairn A, Carmichael A, et al. Preservation of keratin expression in oral mucosa using a novel transport medium. F Oral Pathol Med 1992;21:17-20.

24 Lane EB, Alexander CM. Use of keratin antibodies in tumor diagnosis. Semin Cancer Biol 1990;1:165-79.

25 Morgan PR, Leigh IM, Purkis PE, Gardner ID, Van Muijen GNP, Lane EB. Site variation in keratin expression in human oral epithelia-an immunocytochemical study of individual keratins. Epithelia 1987;1:31-43.

26 Lane EB, Bartek J, Purkis PE, Leigh IM. Keratin antigen in differentiating skin. Ann NY Acad Sci in differentiating

27 Dhouailly D, Xun C, Monabe M, Schermer A, Sun T-T. Expression of hair-related keratins in a soft epithelium: keratinocytes express keratin markers for hair, skin and oesophageal types of differentiation. Exp Cell Res 1989;181:141-58.

28 Stasiak PC, Purkis PE, Leigh IM, Lane EB. Keratin 19: Predicted amino acid sequence and broad tissue distribution suggest it evolved from keratinocyte keratins. $f$ Invest Dermatol 1989;92:707-16.

29 Makin CA, Bobrow LG, Bodmer WF. Monoclonal antibody to cytokeratin for use in routine histopathology. $\mathcal{F}$ Clin Pathol 1984;37:975-83.

30 Lane EB. Monoclonal antibodies provide specific intramolecular markers for the study of epithelial intramolecular markers for the study of epithelial

31 Coghill G, Swanson Beck J, Gibbs JH, Fawkes RS. The Avidin-Biotin technique in immunocytochemical staining. In: Grange JM, Fox A, Morgan NL, eds. Society for Applied Bacteriology. Technical Series 24. Immunological techniques in microbiology. Oxford: Blackwell Scientific Publications, 1987: 87-110.

32 Ogden GR, Cowpe JG, Green MW. A comparison of the Cytobrush and wooden spatula for oral exfoliative cytology. Acta Cytol 1992;36:706-10.

33 Sawaf MH, Ouhayoun JP, Forest N. Cytokeratin profiles in oral epithelia: A review and a new classification. $\mathcal{f}$ Biol Buccale 1991;19:187-98.

34 Morgan PR, Shirlaw PJ, Johnson NW, Leigh IM, Lane EP. Potential applications of antikeratin antibodies in oral diagnosis. $\mathcal{f}$ Oral Pathol 1987;16:212-22.

35 Lucas RB. Pathology of tumours of the oral tissues. 3rd edn. Edinburgh: Churchill-Livingstone, 1976: 140.

36 Lindberg K, Rheinwald JG. Suprabasal $40 \mathrm{kd}$ keratin (K19) expression as an immunohistologic marker of premalignancy in oral epithelium. Am $\mathcal{F}$ Pathol 1989 ,
134:89-98.

37 Nakai M, Mori M. Immunohistochemical distribution of monoclonal antibodies against keratin in papillomas and carcinomas from oral and nasopharyngeal regions. Oral Surg Oral Med Oral Pathol 1986;62:292-302.

38 Vaidya MM, Borges AM, Pradham SA, Rajpal RM Bhissey AN. Altered keratin expression in buccal mucosal squamous cell carcinoma. 7 Oral Pathol Med 1989;18:282-6.

39 Vigneswaran N, Peters K-P, Hornstein OP, Haneke E 
Comparison of cytokeratin, filagrin and involucrin profiles in oral leukoplakias and squamous carcinomas. $f$ Oral Pathol Med 1989;18:337-90.

40 UICC In: Sherman C D Ed. Manual of clinical oncology. 4th Ed. Geneva: Springer-Verlag, 1987.

41 Dabelsteen E, Roed-Petersen B, Smith C J, Pindborg J J. The limitations of exfoliative cytology for the detection of epithelial atypia in oral leukoplakias. $\mathrm{Br} \mathcal{f}$ Cancer 1971;25:21-4.

42 Katz H C, Shear M, Altini M. A critical evaluation of epithelial dysplasia in oral mucosal lesions using the Smith-Pindborg method of standardisation. $\mathcal{f}$ Oral Pathol 1985;14:476-82.

43 Pindborg J J, Reibel J, Holmstrup P. Subjectivity of evaluating oral epithelial dysplasia, carcinoma in situ and initial carcinoma. $\mathcal{F}$ Oral Pathol 1985;14:698-708.
44 Smedts F, Ramaekers F C S, Robben H, et al. Changing patterns of keratin expression during progression of cervical intraepithelial neoplasia. Am $\mathcal{f}$ Pathol 1990; 136:657-68.

45 Markey A C, Lane E B, Churchill L J, MacDonald D M Leigh I M. The expression of simple epithelial keratins 8 and 18 in epidermal neoplasia. $\mathcal{F}$ Invest Dermatol 1991;97:763-70.

46 Heyden A Huitfeldt H S, Koppang H S, Thrane P S, Bryne M, Brandftzaeg $\mathbf{P}$. Cytokeratins as epithelial differentiation markers in premalignant and malignant oral lesions. F Oral Pathol Med 1992;21:7-11.

47 Ogden G R, McQueen S, Lane E B, Green M W, Hopwood D, Chisholm D M. Cytokeratin expression in oral exfoliative cytology-effect of temperature and fixation. Histochem $\mathcal{F}$ 1992;24:176-9. 